\title{
فعالية نموذج تخمين الكلمة لنتائج تعليم اللغة العربية من فصل المتوسط مجلس تنمية اللغة الاجنبية بمنطقة دار اللغة من معهد الاسلام دارالسلام بلوك اكونج السنة
}

\author{
الدراسية (1) \\ جامعة الدار السلام الاسلامية بولكأكونج - بيونجي \\ محمد بشري اخوان'، إإسم ليلي \\ iis@gmail.com,bisri@iaida.ac.id,
}

\section{مستخلص البحث}

هذا البحث مدفوع بظروف تعليم اللغة العربية في معهل دار اللغة لثنمية اللغة

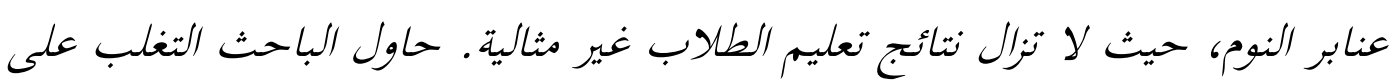
هذه المشكلة من حلال استخحام نماذج التخمين التعاونية لتحسين نتائج تعليم اللغة النة العربية للى الطلاب.

أسئلة البحث في هذه الدراسية هي: (1) كيف تطبيق كلمات التخمين التعاونية

على مواضيع اللغة العربية في موضوع منردات حول هوايات تحسين مخرجات التعليم

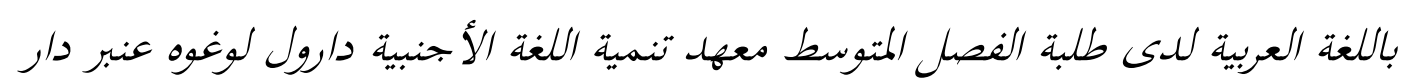

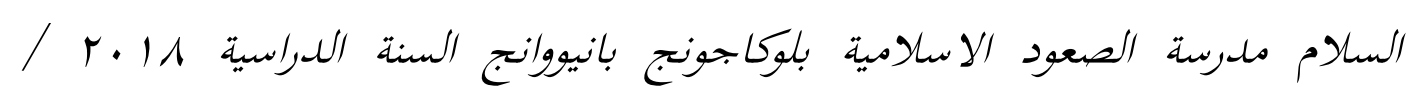

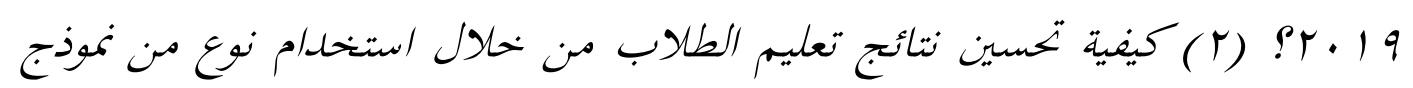
التخمين التعاوني في موضوعات اللغة العربية في فصل المتوسط التابع لمعهد تنمية اللغة

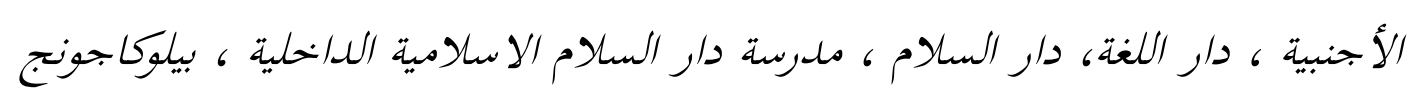

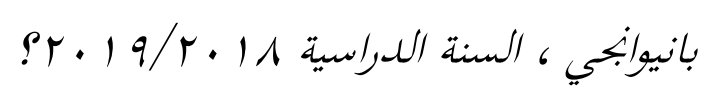

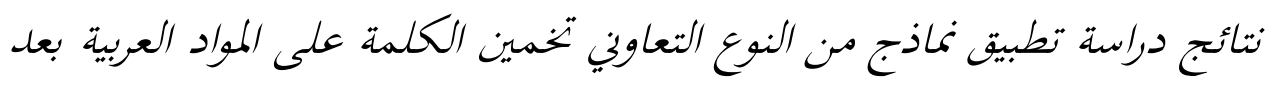
خطوات النشاط الأولي ، وأظهرت الأساسية وكذلك في النهاية زيادة في نتائج التعليم

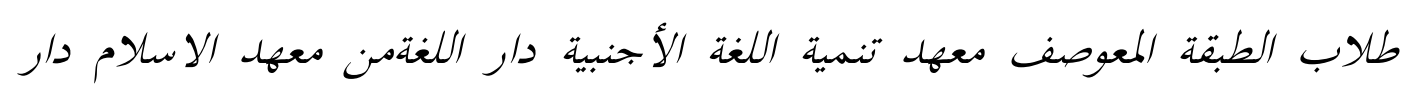

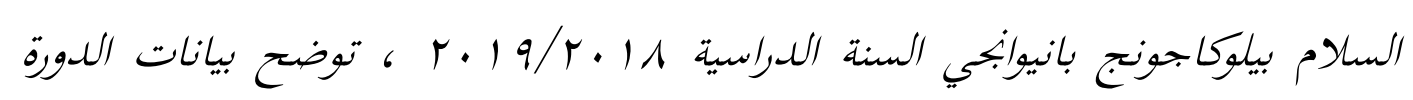




$$
\begin{aligned}
& \text { الأولى أن متوسط قيمة نتائج تعليم الطلاب الإجمالية هو •1 مع نسبة اكتمال قلدها }
\end{aligned}
$$

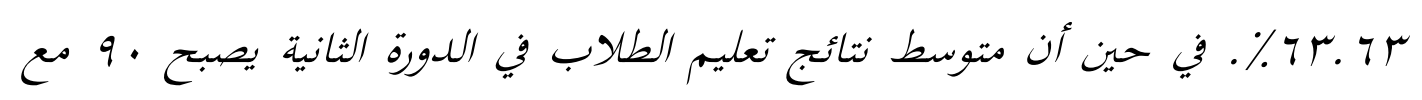

$$
\begin{aligned}
& \text { إجمالي التعليم إتقان الطالب هو } 7 \text { م. } 17 \text { \% } \\
& \text { الكلمات المفتاحية: نموذج تخمين الكلمات ، نتائج التعليم }
\end{aligned}
$$

\begin{abstract}
ABSTRAK
Penelitian ini dilatar belakangi oleh kondisi pembelajaran Bahasa Arab di Lembaga Pengembangan Bahasa Asing Asrama Darul Lughoh, yang hasil belajar siswa masih belum maksimal. Peneliti berusaha mengatasi permasalahan tersebut melalui penggunaan model kooperatif tipe tebak kata untuk meningkatkan hasil belajar Bahasa Arab pada siswa.

Rumusan masalah dalam penelitian ini adalah (1) Bagaimana penerapan model kooperatif tipe tebak kata pada mata pelajaran Bahasa Arab pokok bahasan mufrodat tentang hobi untuk meningkatkan hasil belajar Bahasa Arab siswa kelas mutawassith Lembaga Pengembangan Bahasa Asing Asrama Darul Lughoh Pondok Pesantren Darussalam Blokagung Banyuwangi Tahun Ajaran 2018/2019 ? (2) Bagaimana peningkatan hasil belajar siswa melalui penggunaan model kooperatif tipe tebak pada mata pelajaran Bahasa Arab siswa kelas mutawassith Lembaga Pengembangan Bahasa Asing Asrama darul Lughoh Pondok Pesantren Darussalam Blokagung Banyuwangi Tahun Ajaran 2018/2019.

Hasil penelitian penerapan model kooperatif tipe tebak kata pada mata pelajaran Bahasa Arab setelah melaui langkah-langkah kegiatan awal, inti dan juga akhir menunjukkan adanya peningkatan hasil belajar siswa kelas mutawassith Lembaga Pengembangan Bahasa Asing Asrama darul Lughoh Pondok Pesantren Darussalam Blokagung Banyuwangi Tahun Ajaran 2018/2019. Data dari siklus I menunjukkan nilai rata-rata hasil belajar siswa secara keseluruhan adalah 80 dengan prosentase ketuntasan 63,63\%. Sedangkan pada siklus II rata-rata hasil belajar siswa menjadi 90 dengan ketuntasan belajar siswa keseluruhan adalah 86,36\%.
\end{abstract}

\title{
Kata-kata Kunci : Model Tebak Kata, Hasil Belajar.
}




\section{أ. خلفية البحث}

تعد بحلس تنمية اللغة الأجنبية بمنطقة دار اللغة من معهد الاسلام دار السالام

بلوك اكونج واحدة من أهم مساكن الطلبة في المعهد دار السالام بلوكاجونج التي تتعليم

لغتين أجنبيتين، وهما العربية والإبحليزية. ومع ذلك، في هذه الحالة الطريقة المستخدمة للتعليم لا تزال بسيطة للغاية، وخاصة في تعليم اللغة العربية. بناءً على المقابلة التي أجراها مع الأستاذ صفوة القلب بصفته المعلم الذي يدرس مواد اللغة العربية من فصل المتواسط في بحلس تنمية اللغة الاجنبية بمنطقة دار اللغة من معهد الاسلام دارالسالام، قال إنه استخدم طريقة الأسئلة والأجوبة وكتاب النصوص بشكل متكرر. باستخدام نماذج التعليم معينة .هذا يرجع إلى العديد من المواد العربية والأجنبية. ووفقا له، سيتم فهمه وتذكره بسرعة أكبر عند استخدام طريقة السؤال والإجابة والواجبات. ( مقابلة، م، V،

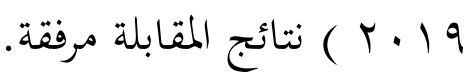

بناءً على هذه المشكالات، يشعر الباحث بالحاجة والدافع لدراسة طريقة جديدة، وهي "تخمين الكلمات" لتحسين التحصيل الدراسي لدى الطلاب اللغة العربية في المنطقة "دار اللغه" في دار المواقف في دار اللغة، وخاصة في موضوع الموايات .لهذا السبب ، أثنار الباحث عمدا عنوان " فعالية نموذج تخمين الكلمة لنتائج تعليم اللغة 
العربية من فصل المتواسط في مجلس تنمية اللغة الاجنبية بمنطقة دار اللغة من معهد

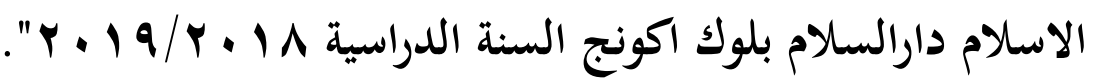
ب. بأسئلة البحث بناءً على خلفية البحث أعلاها ، فإن الأسئة البحث هي كما يلي: ا. كيف تطبيق نموذج تعاوني من نوع التخمين حول مواضع اللغة العبية في موضوع الهوايات لالطلاب من فصل المتواسط في بحلس تنمية اللغة الاجنبية بمنطقة دار اللغة من معهد الاسلام دارالسلام بلوك اكونج السنة الدراسية م ا • / 1 ـ ؟؟؟ r. كيف يمكن تحسين مخرجات تعليم اللغة العربية في موضوع الهوايات لدى الطلاب من فصل المتواسط في بجلس تنمية اللغة الاجنبية بمنطقة دار اللغة من

$$
\begin{aligned}
& \text { معهد الاسلام دارالسلام بلوك اكونج السنة الدراسية م ا • /9 1 • ؟؟ } \\
& \text { ج. أهداف البحث }
\end{aligned}
$$

بناءً على أسئلة البحث أعلاها، تتمثل الأهداف البحثية المراد تحقيقها فيما يلي: ا ـ لوصف تطبيق نماذج النوع التعاوين لتخمين الكلمات في مواضيع اللغة العبية، موضوع هوايات للالطلاب، من فصل المتواسط في بحلس تنمية اللغة الاجنبية بمنطقة دار اللغة من معهد الاسلام دارالسلام بلوك اكونج السنة الدراسية

$$
\cdot r \cdot 19 / r \cdot 11
$$


r. لتحسين مخرجات تعليم اللغة العربية موضوع الهوايات لدى الالطلاب من فصل المتواسط في بحلس تنمية اللغة الاجنبية بمنطقة دار اللغة من معهد الاسلام

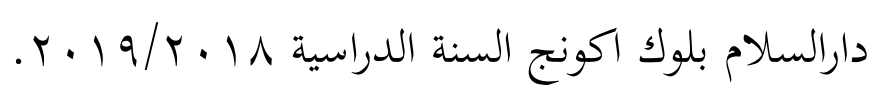

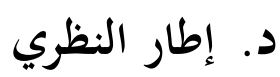

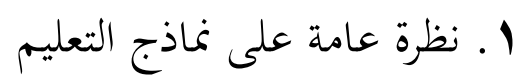

التعلم عبارة عن نظام أو عملية تعلم للطلاب / الدارسين الذين تم تخطيطهم أو تصميمهم وتنفيذهم وتقييمهم بشكل منهجي حتى يتمكن الطلاب / الدارسون من

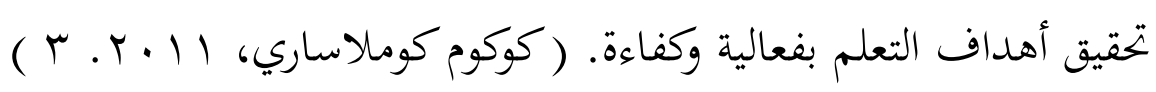
أصليا، يتم تفسير النماذج على أهما أنماط أو خطط أو تمثيلات أو أنظمة أو مفاهيم، والتي غالبا ما تكون في شكل تبسيط أو مثالية. يمكن أن يكون النموذج نموذجًا ماديًا (نموذج أو نموذج أولي) أو نموذج صورة (صورة تصميم أو صورة كمبيوتر) أو صيغة رياضية. النموذج وفقًا لميلز في سوفري جونو هو شكل من أشكال التمثيل الدقيق كعملية حقيقية تسمح لشخص أو بحموعة من الأشخاص بمحاولة التصرف بناءً على هذا النموذج. ( أكوس سوفيجونو، r ا. r. 0ـ ) في حين يشير مصطلح التعلم إلى التفاعل والتواصل بين المعلم والطلاب في الفصل، حيث تحدث عملية إرسال المعلومات أو المعرفة من المعلم لطلاب. ( وينا سنجيا، 


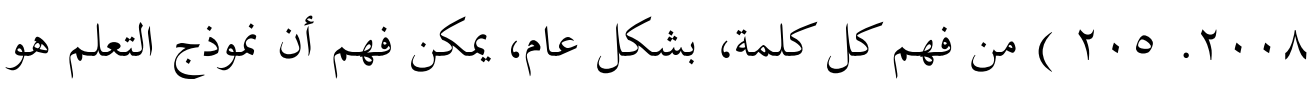
نمط أو وصف لتنفيذ عملية التعلم. علاوة على ذلك، أرندس في هامرون. Y . نظرة عامة على نماذج التعليم التعاوين اكتب كلمات التخمين عملية التعليم والتعلم نشاطان يتمان في نفس الوقت والنطاق. المعلمون والطالاب الذين يتعلمون هم وحدهم في تفاعل تعليمي. ( سيف البحر، ما • r. Nم ) في جوهره التعلم هو عملية تغيير تحدث في الطلاب. أما بالنسبة للفهم النوعي، فالتعلم هو عملية الحصول على معاني وفهم وكيفية تفسير العالم من حول الطلاب. (محبين سة، ه . . ץ. 1 T ) وفي الوقت نفسه، يعتقد رومين في هاماليك أن "التعلم يُعَّف بأنه تعديل أو تعزيز للسلوك من خلال التجربة". (اومار هامليك،

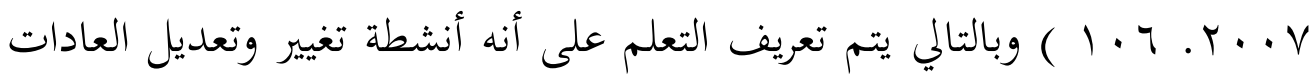
والخبرات. بينما يشير التعليم إلى عملية تنظيمية، وهي تنظيم أنشطة تعلم الطلاب وتنظيمها.

المعلم باعتباره الشخص الذي يتصرف لتعليم الطلاب هو الشخصية الرئيسية في التعلم. يتأثر بجاح أو فشل أنشطة تعلم الطلاب إلى حد كبير بالطريقة التي يعلم بها المعلم وينظم الفصل. في تصميم أنشطة التعلم لتكون فعالة ضد الأهداف المراد 
تحقيقها، يستخدم المعلمون المطلقون نماذج التعلم بكيث تكون أنشطة التعلم أكثر

$$
\text { فعالية وكفاءة. }
$$

ץ. نظرة عامة على نتائج التعليم

يعرف ريبير في محبين التعلم في تعريفين. أولاً، يُعرّف التعلم بأنه عملية اكتساب

المعرفة. يستخدم هذا الفهم في كثير من الأحيان في مناقشات علم النفس المعرفي

الذي يعتبره بعض الخبراء أقل تمثيلا لأنه لا يشمل اكتساب مهارات غير معرفية. )

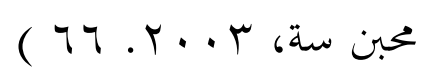

ثانيًا، التعلم هو تغيير دائم نسبيًا في الاستجابة المحتملة التي تحدث نتيجة لظروف

الممارسة المعززة (تغيير دائم نسبيًا في القدرة على التفاعل كنتيجة معززة للتمرين). في

هذا التعريف، هناك أربعة أنواع من المصطلحات ضرورية وتحتاج إلى تسليط الضوء

عليها لفهم عملية التعلم. المصطلح دائم نسبيًا، الدلالة هي أن التغييرات مؤقتة مثل

التغييرات بسبب السكر والتعب والتشبع والتغيير لأن النضج الجسدي لا يشمل

التعلم. قد يعني مصطلح الاستجابة إظهار الاعتراف بالفرق بين التعلم والمظهر أو

أداء مخرجات التعلم. المصطلح يعزز الدلالة على أن القدرة ضعيفة جدًا إذا لم يتم

منحها التعزيز. في الوقت نفسه، يُظهر الفصل الأخير، الممارسة، أن عملية التعلم 
تتطلب ممارسة تميل إلى أن تكون متكررة لضمان استدامة الأداء الأكاديمي التي

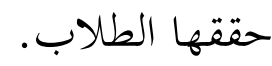
ع ـ نظرة عامة على دروس اللغة العربية

الموضوعات العربية هي مواضيع موجهة نهو تشجيع وتوجيه وتطوير وتنمية القدرات وتعزيز موقف إيجابي تجاه اللغة العربية المستقبلة والمثمرة. القدرة الاستقبالية هي القدرة على فهم محادثات الآخرين وفهم القراءة. القدرة الإنتاجية هي القدرة على استخدام اللغة كأداة اتصال شفهية وخطية. في المساعدة على فهم مصادر التعاليم الإسلامية، أي القرآن، الحديث، والكتب الأخرى المتعلقة باللغة العربية، يجب أن يكون لدى الطلاب القدرة على التحدث باللغة العربية. (تنظيم وزير الدين

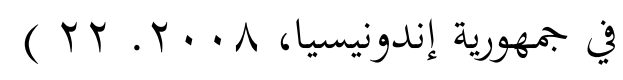
بناءً على ذلك، يتم إعداد اللغة العربية في مدارس المدارس، وخاصة الأماكن التي تتحدث بها اللغة، لتحقيق الكفاءة اللغوية الأساسية، والتي تشمل أربع مهارات لغوية يتم تدريسها بشكل متكامل، وهي الاستماع والتحدث والقراءة والكتابة. ومع ذلك، يركز التعليم الابتدائي على مهارات الاستماع والتحدث كأساس لغوي. على مستوى التعليم الثانوي، يتم تدريس جميع المهارات اللغوية الأربع بطريقة متوازنة. ثم 
في المستوى المتقدم، يتم التركيز على مهارات القراءة والكتابة، لذلك من المتوقع أن يتمكن الطلاب من الوصول إلى مختلف المراجع العربية. ه. تطبيق نموذج التعاونية تخمين الكلمات في تعليم اللغة العربية

كمحترف، يجب أن يكون لدى المعلم المعرفة وجرد استراتيجيات التعلم. ليست كل نماذج التعلم التي يعرفها ويجب تطبيقها في الواقع اليومي في الفصل الدراسي. على الرغم من ذلك، لن يتم تركيز المعلمين الجيدين على نموذج تعليمي واحد فقط. يحتاج المعلمون الذين يرغبون في التقدم والتطور إلى امتلاك نماذج تعليمية وتقنيات التعلم التي ستكون بالتأكيد مفيدة دائمًا في تنفيذ أنشطة التعليم والتعلم اليومية. (

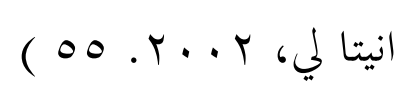

\section{هـ مـهجية البحث}

نوع البحث الذي سيتم إجراؤه بواسطة البحث هو الفصل الدراسي لأبحاث العمل والذي يطلق عليه البحث الحركية باللغة الإبحليزية الفصل الدراسي للأبحاث النشطة. البحث في الفصل الدراسي يأتي من ثلاث كلمات هي: البحث، العمل،

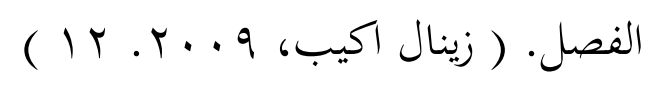
وفقًا لأحمد تنزه، يعد البحث وسيلة التطوير العلوم، سواء من حيث النظريين أو العمليين. ( احمد تنزية، و . . Y. Y I ) بينما يتم تفسير الإجراءات على أها حركة 
أنشطة يتم تنفيذها عن قصد بهدف محدد، في شكل سلسلة من دورات الأنشطة للطلاب. ( ريدو كورنيانتو، 9. . . . T I ) تتلقى بحموعة من الطلاب في نفس

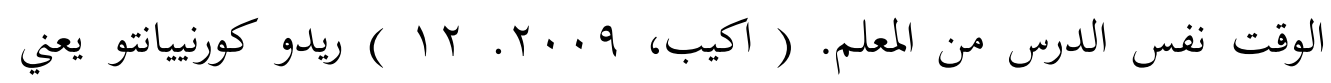
ببساطة أن الفصل عبارة عن غرفة يتعلم فيها المعلم ويتعلم الطلاب. ( كورنييانتو، $(9 \cdot r \cdot \cdot q$ من التعريف الثالث للكلمة، أي البحث والعمل والحصة، يمكن أن نستنتج أن البحث عن العمل في الفصل هو شكل من أشكال البحث الذي يعكس، من خلال اتخاذ إجراءات معينة يمكن أن يحسن عملية التعليم في الفصل. البحث في الفصل هو استخدام نوع من دراسة الحالة. دراسة حالة لفصل دراسة الحالة هي نوع من البحث الإجرائي الذي يهدف إلى اكتشاف واستكشاف وتحليل وإيجاد أفضل الحلول الصحيحة أو الحلول للتغلب على مشكلة. ( جاسا اوعكوة

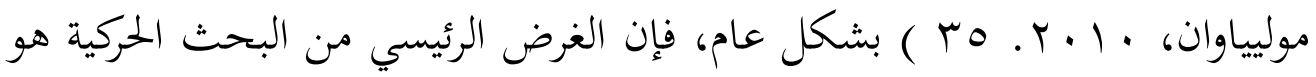
تحسين جودة التعليم، وليس لإنتاج المعرفة. يتضمن تحسين جودة التعليم الوعي

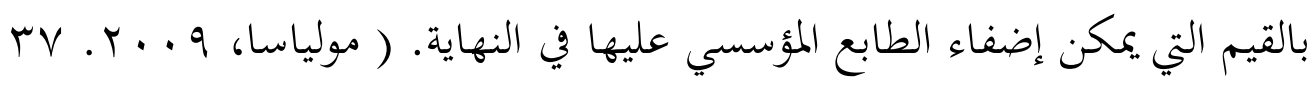


يتم إجراء هذا البحث في الفصل الدراسي بالتعاون، ويستند هذا إلى البحث الذي يتم في أزواج بين الأطراف التي تتخذ الإجراءات وتلك التي تراقب مسار العمل. يقال إن البحث التعاوني مثالي بسبب الجهود المبذولة لتقليل العنصر الشخصي للمراقب وكذلك جودة دقة الملاحظات التي تم إجراؤها .( سوهارسيني اريكونتو، . . . . IV ) في البحث التعاونية، يكون الطرف الذي يتخذ الإجراءات هو الباحث، بينما الشخص الذي يُطلب منه مراقبة عملية العمل المستمرة هو مدرس المادة. استنادًا إلى نوع البحث الموضح سابقًا، يستخدم تصميم البحث الحركية أو التصميم المستخدم نموذج البحث الحركية كيميس و تاغارت في تدفق البحث الذي

$$
\begin{aligned}
& \text { يشمل: ( اريكونتو، · ( • ( . } 17 \text { ) } \\
& \text { 1. التخطيط (الخطة) }
\end{aligned}
$$

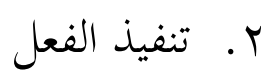




\section{و. مناقشة نتائج البحث}

تطبيق نوع النموذج التعاوني يخمن المفردات حول الهوايات في فصل المواسم.

يتكون معهد تطوير اللغات الأجنبية من دورتين. وبتحى كل دورة لاجتماع واحد.

ينقسم كل اجتماع إلى ثلاث مراحل ، وهي المراحل الأولية والأساسية والنهائية.

المرحلة الأولى تشمل أنشطة الإدراك التي يقوم بها الباحثون الذين يقومون بدور

المعلمين. تشمل المرحلة الأساسية ما يلي: (1) يقدم الباحث شرحًا للأهداف

التعليمية المراد تحقيقها ، r ) يشارك الباحث الوسائط الهزلية ، r) يشرح الباحث

الموضوع بشكل عام ، §) يقسم الباحث الطلاب في أزواج ، 0) يطلب الباحث

من كل بحموعة من المحموعات وصل إلى مقدمة الفصل وقم بالكلمات التخمينية ،

4) يعطي الباحث تأكيدًا ومفاهيم إضافية تتعلق بتخمينات الكلمات التي أدلى بها

المرحلة النهائية ، وهي: تقديم أسئلة اختبار التكوين بشكل فردي في هاية

الدورة. تم إجراء الاختبار لتحديد مدى إبحاز واكتمال تعلم الطلاب بعد تطبيق

$$
\text { نموذج التخمين التعاوني. }
$$

في تنفيذ الدورة الأولى والدورة الثانية ، تم تنفيذ هذه المراحل وقدمت تحسينات

إيجابية في الطلاب. يتضح هذا من خلال نشاط الطلاب في تعلم اللغة العربية في 
الفصل ، على سبيل المثال الطلاب الذين كانوا في الأصل سلبية في تعلم الأسئلة والأجوبة أصبحت نشطة. الطلاب مستقلون بشكل متزايد في العمل على أسئلة اختبار ما بعد المقدمة من الباحث. بناءً على نشاط الطلاب في الأنشطة التي تم تنفيذها ، يظهر زيادة في كل إجراء. تؤثر التغييرات الإيجابية في نشاط الطلاب أيضًا

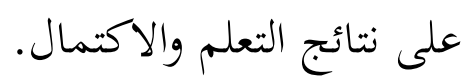
ز. الحخلاصة

بناءً على البحث الذي تم القيام به ، يمكن استنتاج أن تطبيق نموذج من النوع التعاوني الذي يخمن الكلمات للدار اللغة في فصل المتوسط بمنطقة دار اللغة، معهد الإسلام دار السلام بيلوكاجونج، بانيووانغي، عن موضوع هواية، من خلال: ( ) النشاط الأولي: يبدأ الباحث بقول التحيات، وينقل الغرض من التعلم، ويخفز الدار اللغة، ويقدم شرحًا لنوع كلمات التخمين النموذجية التعاونية، وإدراكًا حول المادة المراد تسليمها. ؟ ب) الأنشطة الأساسية: يكتب الباحث المفردات ويقرأها متبوعًا بالدار اللغة، ثم يوزع الباحث وسائط البطاقة، وينقسم الدار اللغة إلى أزواج، ويأتي كل زوج إلى مقدمة الفصل لتخمين الكلمة، في المرحلة التالية يعطي الباحث التعزيز والتأكيد فيما يتعلق بتنفيذ الكلمة التخمين ، ؟) النشاط الختامي: يرشد الباحث الدار اللغة 


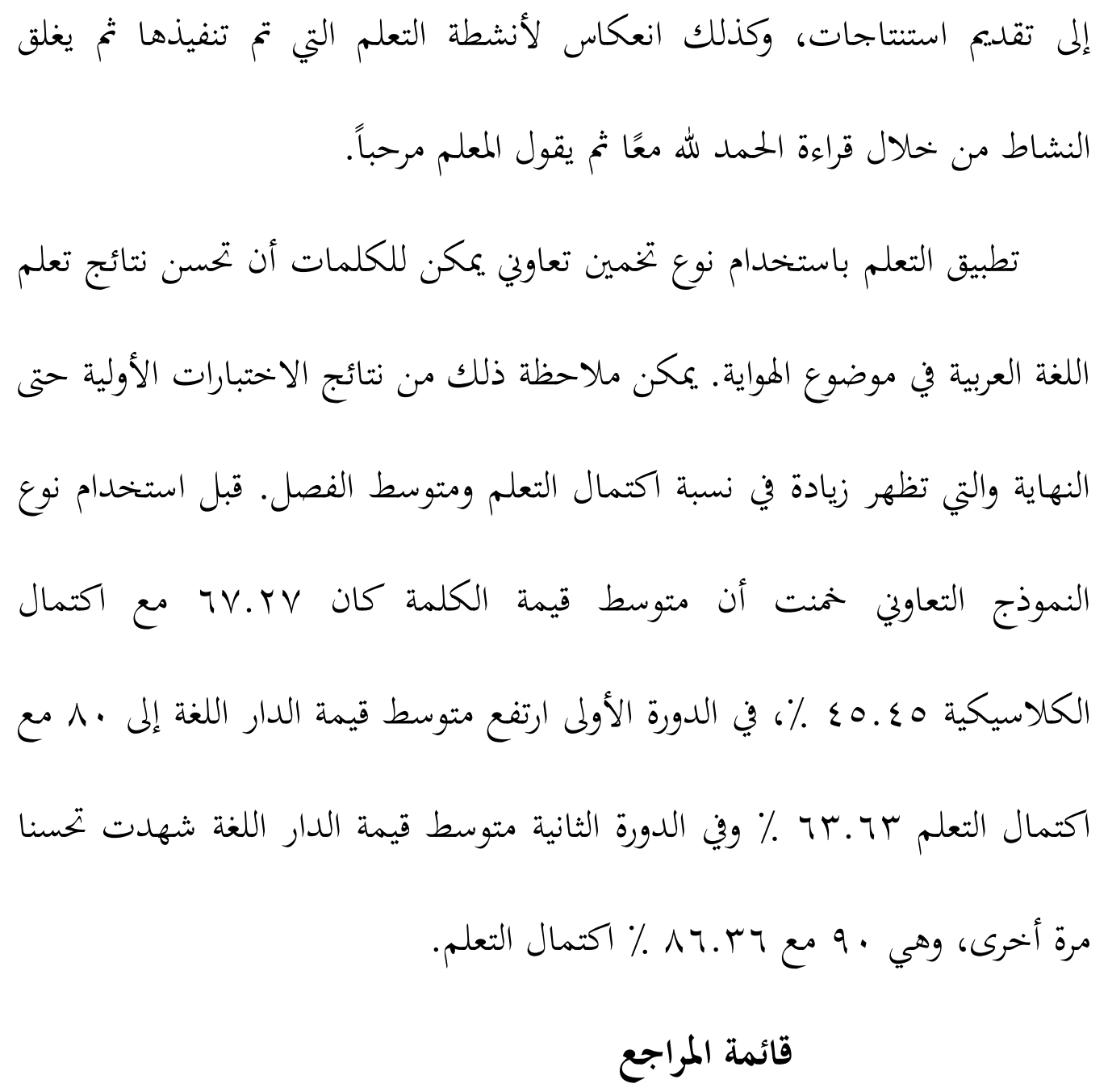

Ali, Nur dan Wahidmurni. 2008. Penelitian Tindakan Kelas Pendidikann Agama dan Umum dari Teori Menuju Praktik Disertai Contoh Hasil Penelitian. Malang: UM press.

Aqib, Zainal. 2013. Model-Model, Media, dan Strategi Pembelajaran Kontekstual Inovatif. Bandung: Yrama Widya.

Arikunto, Suharsimi, et. all. 2010. Penelitian Tindakan Kelas. Jakarta: Bumi Aksara.

Daryanto. 2012. Media Pembelajaran. Bandung: Satu Nusa.

Musthofa, Syaiful. 2013. Strategi Pembelajaran Bahasa Arab Inovatif. Jakarta: Rineka Cipta.

Hamid, Abdul. 1989. Mengukur Kemampuan Bahasa Arab. Bandung : Mandar maju. 
Hamruni. 2012. Strategi Pembelajaran Lie, Anita. 2002. Cooperative Learning: Mempraktikan Cooperative Learning Di Ruang-Ruang Kelas. Jakarta: PT Gramedia.

. Yogyakarta: Insan Madani.

Hastuti, Tri. 2011. Peningkatan Hasil Belajar Pkn Melalui Strategi Tebak Kata Pada Siswa Kelas IV SDN 02 Pereng Kecamatan Mojogedang Kabupaten Karanganyar Tahun Pelajaran 2010/201. Karanganyar: Skripsi Tidak Diterbitkan.

Kurnianto, Rido, et.all. 2009. Penelitian Tindakan Kelas. Surabaya: Lapis PGMI.

Kurniasari, Nur. 2014. Penggunaan Metode Tebak Kata dan Media Kartu Kata Untuk Meningkatkan Pembelajaran IPS Pada Siswa Kelas III SDN Muktisari. Surakarta: Skripsi Tidak Diterbitkan.

Moleong, Lexy J. 2008. Metodologi Penelitian Kualitatif. Bandung : Remaja Rosdakarya.

Muliawan, Jasa Ungguh. 2010. Penelitian Tindakan Kelas. Yogyakarta: Gava Media.

Muhid, Abdul. 2008. Anaqlisis Statistik. Bandung: Remaja Rosdakarya.

Mulyasa, E.. 2009. Praktik Penelitian Tindakan Kelas. Bandung: Remaja Rosdakarya.

Sukardi. 2012. Metodologi Penelitian Pendidikan. Jakarta: Rajawali Pers.

Santoso, Ras Eko Budi. "Model Pembelajaran Cooperative Learning", dalam http://www.ras-eko.com/model-pembelajaran-cooperative-learning-tebak kata.html/, diakses 14 Juli 2019

Siswono, Tatag Yuli Eko Mengajar \& Meneliti. 2008. Surabaya: Unesa University Press.

Solihatin, Etin. 2007. Cooperative Leraning. Jakarta: Bumi Aksara.

Sudjana, Nana. 2008. Penilaian Hasil Belajar Mengajar. Bandung: PT Remaja Rosdakarya.

Sugiyono. 2008. Metodologi Penelitian Kuantitatif dan Kualitatif. Bandung: Alfabeta.

Sukardi. 2008. Metodologi Penelitian Pendidikan. Yogyakarta : Bumi aksara. 
Suprijono, Agus. 2012. Cooperatve LearningTeori dan Aplikasi PAIKEM. Yogyakarta: Pustaka Susilo. 2007. Penelitian Tindakan Kelas. Yogyakarta: Pusstaka Book Publisher.

Syah, Muhibbin. 2003. Psikologi Belajar. Jakarta: RajaGrafindo Persada.

Tanzeh, Ahmad. 2009. Pengantar Metode Penelitian. Yogyakarta: Teras.

Turniasih. 2013. Keefektifan Penerapan Model Tebak Kata Terhadap Minat Dan Hasil Belajar Pkn Materi Komponen Pemerintahan Pusat Di Indonesia. Tegal: Skripsi Tidak Diterbitkan.

Uno Hamzah B., et.all.. 2011. Menjadi Peneliti PTK yang Profesional. Jakarta: Bumi Aksara. 